\title{
Influences of Saturation and Wetting-Drying Cycle on Mechanical Performances of Argillaceous Limestones from Liupanshan Tunnel, China
}

\author{
Bo Meng $\mathbb{D}^{1},{ }^{1}$ Hongwen Jing $\mathbb{D}^{1},{ }^{1}$ Wenxin Zhu, ${ }^{1,2}$ and Haijian Su $\mathbb{C}^{1}$ \\ ${ }^{1}$ State Key Laboratory for Geomechanics and Deep Underground Engineering, China University of Mining and Technology, \\ Xuzhou 221116, China \\ ${ }^{2}$ School of Traffic and Civil Engineering, Shandong Jiaotong University, Jinan 250357, China
}

Correspondence should be addressed to Hongwen Jing; hwjingcumt@163.com

Received 27 May 2019; Accepted 24 July 2019; Published 8 August 2019

Academic Editor: Antonio Riveiro

Copyright (c) 2019 Bo Meng et al. This is an open access article distributed under the Creative Commons Attribution License, which permits unrestricted use, distribution, and reproduction in any medium, provided the original work is properly cited.

Water-rock interaction is a vital factor to affect the stabilities of rock projects. This paper conducted a series of experiments on argillaceous limestones to investigate the influences of saturation and wetting-drying cycle on the physical and mechanical performances of rocks. The results show that the increasing saturation increases the dissolution of clay minerals and lubrication among mineral grains, resulting in an obvious reduction effect on the strength and deformation performances of argillaceous limestones. Wetting-drying cycle increases the porosity and changes the pore structure of argillaceous limestones, leading to the pore transformation from small pore $(0.01 \sim 0.1 \mu \mathrm{m})$ to relatively large pore $(0.1 \sim 1.0 \mu \mathrm{m})$. Both the physical and mechanical performances of argillaceous limestones are weakened by the wetting-drying cycle. Besides, the variation process of the physical and mechanical parameters, including mass loss, density, ultrasonic velocity, compression strength, peak strain, elasticity modulus, and secant modulus, can be divided into two stages: $0 \sim 6^{\text {th }}$ wetting-drying cycle, gently changing, and $6^{\text {th }} \sim 12^{\text {th }}$ wettingdrying cycle, drastically changing. The whole change process of these physical and mechanical parameters with the increase in the wetting-drying cycle number can be expressed with the exponential function in general.

\section{Introduction}

The performance of rocks is affected by the geologically buried environment, e.g., temperature, corrosion, and water [1-4]. In the rich-water geological region, the water-rock interaction is a considerable effect to influence the stability of rock masses in projects [5-9]. For the water-rock interaction, the role of water content of rocks has a basic insight. Li et al. [10] reported the influence of water content on the strength and deformation properties of metasiltstone and metasandstone specimens according to the triaxial compressive tests. The reduction of strength by water content is related to friction angle and $m_{i}$ value in the Mohr-Coulomb and Hoek-Brown failure criterions, respectively. Based on the semicircular bending (NSCB) tests, Zhou et al. [11] revealed the quasistatic fracture behavior of sandstones affected by different water extents (ranging from
0 to $3.5 \%)$. Secondly, water usually has certain chemical corrosion to the rocks due to the industry pollution, which cannot be neglected. Li et al. [12] proposed a chemical damage model to predict the long-term strength of rock masses through the chemical-mechanical simulation tests. Han et al. [13] investigated the damage mechanism and mechanical properties of sandstone specimens from a Chinese riverbank slope under the coupling effects of chemical solution and rapid freeze-thaw cycle. Cai et al. [14] studied the changes in mechanical property and porosity of sandstones subjected to chemical erosion under different $\mathrm{pH}$ values, according to the uniaxial mechanical tests and nuclear magnetic resonance (NMR). Besides, the water, especially confined water, possesses the permeation effect to the rock $[15,16]$. Bidgoli and Jing [17] evaluated the effect of water pressure on the strength and deformation parameters of fractured rock masses using the discrete element method 
(DEM). Cheng et al. [18] presented the failure mechanism of granites from Alxa area of China, under different confinements and water pressures.

In some specific natural engineering environments such as water-level fluctuation in reservoir or dam and seasonal rainfall, the wetting-drying cycle phenomenon is very common to the rock, which has recently become the issue of interest among researchers [19-21]. In this paper, the conventional triaxial compression tests with different confining pressures are firstly conducted on the argillaceous limestone specimens, collected from the Liupanshan tunnel, China, to investigate the effect of saturation on the mechanical performances. Then, the physical and mechanical performances, and microscopic feature of argillaceous limestones subjected to wetting-drying cyclic treatment, are experimentally analyzed in detail, according to the measurements of mass, density and ultrasonic wave, uniaxial compression, and scanning electron microscope (SEM) tests. Finally, NMR tests are also conducted on the argillaceous limestones to investigate the influence of cyclic wetting-drying on the variations in porosity and pore structure.

\section{Experimental Method}

The argillaceous limestone was collected from the Liupanshan tunnel, located in the Ningxia Autonomous Region in northwest China, as shown in Figure 1. The outcrop strata in the tunnel site are mainly Cretaceous, tertiary and quaternary accumulations overlying the bedrock. The tunnel mainly passes through Cretaceous strata, whose lithology is mainly composed of conglomerate, sandstone, argillaceous limestone, and argillaceous sandstone. Around the sampling location, the maximum horizontal principal stress is between 9.98 and $16.68 \mathrm{MPa}$, the minimum horizontal principal stress is between 6.0 and $11.0 \mathrm{MPa}$, and the vertical stress is between 7.0 and $13.0 \mathrm{MPa}$. The tunnel area is rich in groundwater, mainly manifesting as the quaternary loose rock pore water, clastic rock weathering fissure water, bedrock fissure water, fracture zone structure fissure water, and so on. Meanwhile, the climate is provided with the obvious feature of seasonal rainfall, leading to the continuous cycle effect of wetting-drying on the rock mass in tunnels. The collected argillaceous limestone is gray in a natural state, with the main mineral composition of quartz, silica, dolomite, and calcite. The chemical compositions of this argillaceous limestone are listed in Table 1.

After drilling, cutting, and polishing in the laboratory, the argillaceous limestone block was processed into the standard cylinder specimens with the diameter and height of $50 \mathrm{~mm}$ and $100 \mathrm{~mm}$, respectively, as shown in Figure 2(a). The prepared argillaceous limestone specimens were divided into two groups to study the saturation effect and the cycle effect of wetting-drying, respectively.

To study the saturation effect, the specimens were firstly filled with the water under the pressure of $90 \mathrm{~Pa}$ for 72 hours, using a BH-1 vacuum pressure saturation device. Then, the specimens were taken out from the saturation device and were immediately utilized to conduct the conventional triaxial compression tests, with the confining pressures of $0,5,10$, and
$15 \mathrm{MPa}$, respectively, using a RTX-4000 GCTS rock mechanics test system (Figure 2(b)). The maximum loading capacities of axial load and confining pressure of this system are $4000 \mathrm{kN}$ and $140 \mathrm{MPa}$, respectively. A micro-II rock acoustic emission testing device made by PAC (Physical Acoustic Corporation) was also provided for the rock mechanics test system.

For the cycle effect of wetting-drying, the argillaceous limestone specimens were firstly saturated in the water for 3 days and then dried in the natural state for 3 days [22-24]. This process was defined as a cycle of wetting-drying. A total of 12 cycles of wetting-drying were conducted on the specimens. After each cycle, the mass, density, and ultrasonic velocity were measured. The prepared argillaceous limestone specimens after different cycles of wetting-drying were firstly used to conduct the NMR tests to obtain the pore features, using a Macro MR12-150H-I low-field NMR test system. Then, the uniaxial compression tests were carried out at a constant loading rate of $2 \times 10^{-3} \mathrm{~mm} / \mathrm{s}$ to investigate the influence of the wetting-drying cycle on the mechanical performances. Before testing, the acoustic emission (AE) sensor was installed on the surface of the specimens to collect the acoustical information during the loading process. Besides, the natural specimens, without saturated water, were also tested as the reference.

\section{Influence of Saturation on the Mechanical Performances}

The variations in the triaxial compression strength $\sigma_{\mathrm{s}}$ and elasticity modulus $E_{\mathrm{a}}$ of the argillaceous limestone specimens in the saturated and natural states, respectively, with different confining pressures $\sigma_{3}$, are shown in Figure 3. With the increment of confining pressure, both the triaxial compression strength and elasticity modulus present the approximately linear increasing trends. As the confining pressure increases from 0 to $15 \mathrm{MPa}$, the triaxial compression strength increases from 56.56 to $129.83 \mathrm{MPa}$ for the saturated state and from 82.47 to $165.64 \mathrm{MPa}$ for the natural state, by the rates of $129.54 \%$ and $100.85 \%$, respectively. The elasticity modulus increases from 5.69 to $8.12 \mathrm{GPa}$ for the saturated state and from 8.89 to $13.08 \mathrm{GPa}$ for the natural state, by the rates of $42.71 \%$ and $47.13 \%$, respectively.

Figure 3 shows that the saturation has the obvious attenuating effect on the strength and deformation performances of the argillaceous limestone specimens. Compared with the natural state, the triaxial compression strength for the saturated state decreases by $31.42 \%\left(\sigma_{3}=0 \mathrm{MPa}\right), 25.15 \%\left(\sigma_{3}=5 \mathrm{MPa}\right)$, $24.63 \%\left(\sigma_{3}=10 \mathrm{MPa}\right)$, and $21.62 \%\left(\sigma_{3}=15 \mathrm{MPa}\right)$, respectively. Similarly, the elasticity modulus decreases by $36.00 \%$ $\left(\sigma_{3}=0 \mathrm{MPa}\right), 47.85 \%\left(\sigma_{3}=5 \mathrm{MPa}\right), 47.78 \%\left(\sigma_{3}=10 \mathrm{MPa}\right)$, and $37.92 \%\left(\sigma_{3}=15 \mathrm{MPa}\right)$, respectively.

Based on the linear Mohr-Coulomb (M-C) strength criterion (equation (1)), the cohesion $c$ and friction angle $\varphi$ of argillaceous limestones were obtained, as shown in Figure 4:

$$
\sigma_{\mathrm{s}}=\frac{2 c \cos \varphi}{1-\sin \varphi}+\frac{1+\sin \varphi}{1-\sin \varphi} \sigma_{3} .
$$

In the natural state, the argillaceous limestone has the constant cohesion and friction angle of $18.61 \mathrm{MPa}$ and $43.08^{\circ}$, 


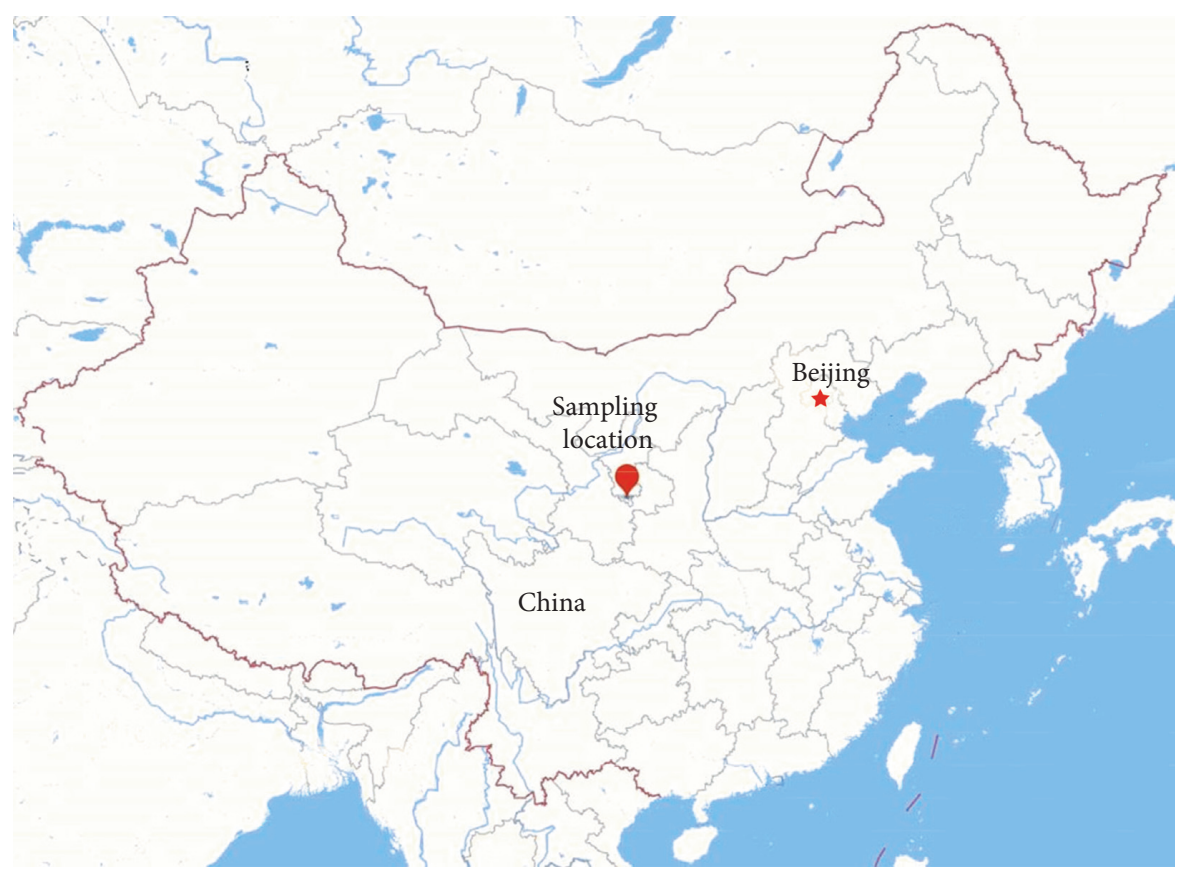

Figure 1: Sampling location of argillaceous limestone in this study.

TABle 1: Chemical compositions of argillaceous limestones.

\begin{tabular}{lccccccc}
\hline $\mathrm{SiO}_{2}$ & $\mathrm{CaO}$ & $\mathrm{Al}_{2} \mathrm{O}_{3}$ & $\mathrm{MgO}$ & $\mathrm{Fe}_{2} \mathrm{O}_{3}$ & $\mathrm{~K}_{2} \mathrm{O}$ & $\mathrm{Na}_{2} \mathrm{O}$ & $\mathrm{Others}$ \\
\hline $45.85 \%$ & $18.28 \%$ & $13.70 \%$ & $10.44 \%$ & $5.80 \%$ & $2.30 \%$ & $1.53 \%$ & $2.09 \%$ \\
\hline
\end{tabular}

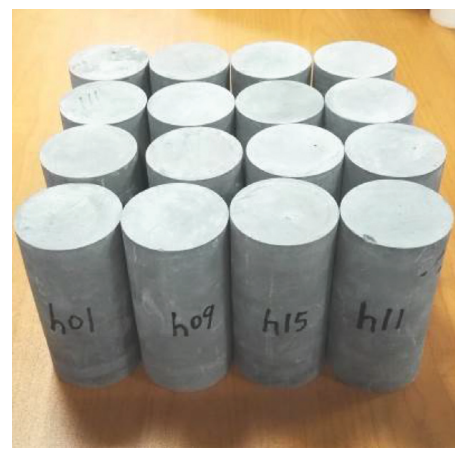

(a)

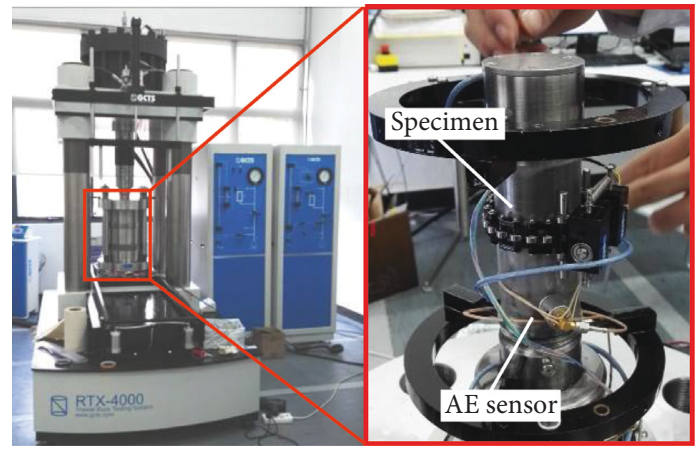

(b)

Figure 2: (a) Argillaceous limestone specimens and (b) RTX-4000 GCTS rock mechanics test system.

respectively. However, in the saturated state, both the cohesion and friction angle show decreasing trends, by the rates of $25.90 \%$ and $6.59 \%$, respectively. The degradation effect of saturations can be attributed to two reasons. One is that some clay minerals, which widely exist in the argillaceous rock, are dissolved in the water, leading to the increasing porosity and structural damage of rocks. The other reason is that the lubrication performance of water in rocks decreases the friction among the mineral grains, resulting in the attenuation of bearing capacity of argillaceous limestones.

\section{Cycle Effect of Wetting and Drying}

4.1. Physical Performances. The performance of argillaceous limestones, which does not just depend on the saturated state, is also influenced by the cycle effect of wetting-drying. In order to visually investigate the variation in the mass of argillaceous limestone treated by the wetting-drying cycle, mass loss level was defined as

$$
k=\frac{m_{\mathrm{n}}-m_{c}}{m_{\mathrm{n}}} \times 100 \%
$$




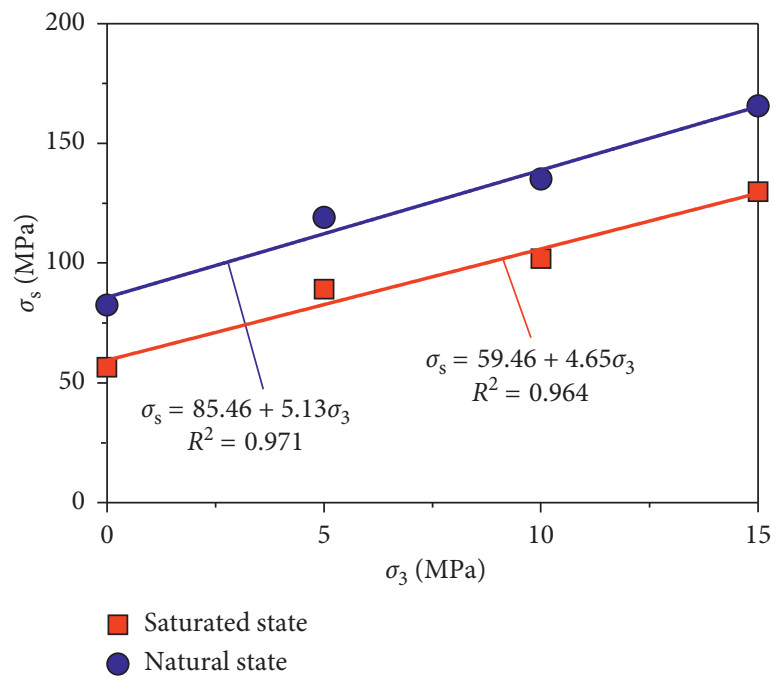

(a)

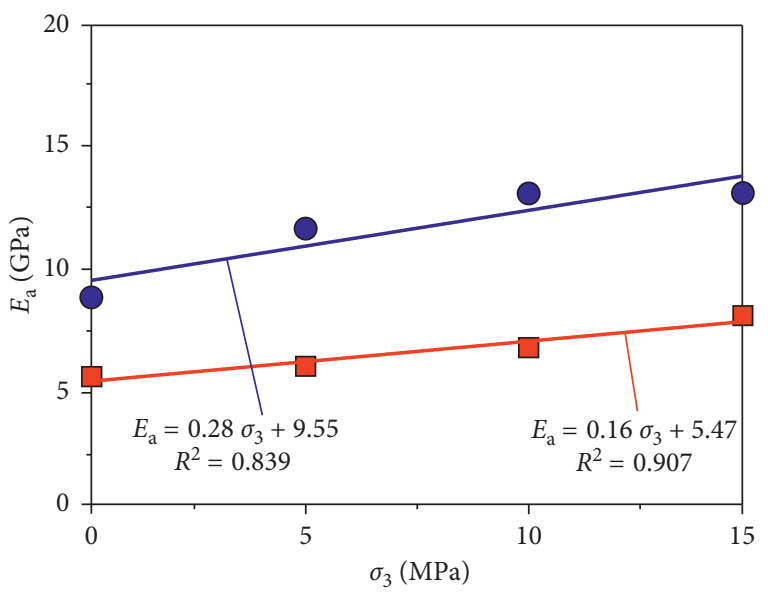

Saturated state

Natural state

(b)

FIGURE 3: Effect of confining pressure on the (a) triaxial compression strength and (b) elasticity modulus of the argillaceous limestone specimens in the saturated and natural states, respectively.

where $k$ is the mass loss level and $m_{\mathrm{n}}$ and $m_{\mathrm{c}}$ are the masses in the natural state and after the wetting-drying cycle, respectively.

Figure 5 shows the variation in mass loss level of the argillaceous limestone specimens with different wetting-drying cycle number $N$. With the increase in $N$, mass loss level increases gradually in general. In the cycle process of wettingdrying, some mineral grains, especially clay minerals, are carried away from the specimen, companying with the water. The gradual loss of mineral grains inevitability leads to the reduction in mass $[25,26]$. According to the changing trend of mass loss level, two stages can be further identified: stable influencing stage $\left(0^{\text {th }}-6^{\text {th }}\right)$ and drastic influencing stage $\left(6^{\text {th }}-\right.$ $12^{\text {th }}$ ), as shown in Figure 5. As $N$ rises from 0 to 6 , mass loss level presents a stable increasing trend and increases by $0.52 \%$. However, when $N$ rises from 6 to 12, mass loss level drastically changes and increases from $0.52 \%$ to $1.86 \%$. This phenomenon illustrates that the damaging effect of the wetting-drying cycle on the physical performances of argillaceous limestones is exhibited in a staged way, instead of a continuous way. This sectionalized feature is impacted by the content of clay minerals, cementing property among the mineral grains, interaction between water and clay mineral, and so on.

Variations in density and ultrasonic velocity of argillaceous limestones with different $N$ are shown in Figure 6. With the increase in $N$, density and ultrasonic velocity decrease gradually. As $N$ rises from 0 to 12 , density decreases from 2.51 to $2.46 \mathrm{~g} / \mathrm{cm}^{3}$, and ultrasonic velocity decreases from 3.6 to $2.01 \mathrm{~km} / \mathrm{s}$, with the reduction extents of $1.91 \%$ and $44.10 \%$, respectively. Before and after the $6^{\text {th }}$ wettingdrying cycle, ultrasonic velocity also shows the sectionalized feature, which is similar to the mass loss. Generally, the variations in mass loss level, density, and ultrasonic velocity with the increase in $N$ can be expressed by the exponential function, with the correlation coefficients of $0.99,0.98$, and 0.98, respectively, as shown in Figures 5 and 6.

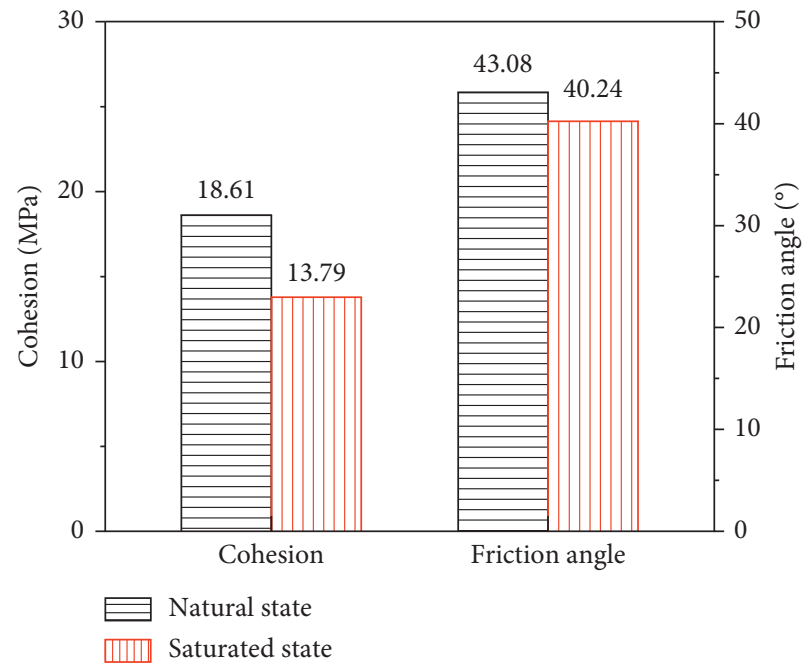

FIGURE 4: Cohesion and friction angle of argillaceous limestone in the natural and saturated states, respectively.

4.2. Mechanical Performances. The variations in compression strength $\sigma_{0}$, peak strain $\varepsilon_{0}$, elasticity modulus $E_{\mathrm{a}}$, and secant modulus $E_{50}$ of the argillaceous limestone specimens after the wetting-drying cycle under uniaxial compression are shown in Figure 7, and the detailed values are listed in Table 2, in which the peak strain indicates the axial strain under a peak axial stress. With the increase in $N$, all the compression strength, elasticity modulus, and secant modulus decrease gradually, while the peak strain increases. As $N$ increases from 0 to 12 , the compression strength decreases from 81.83 to $51.25 \mathrm{MPa}$, by a rate of $37.37 \%$. The elasticity modulus decreases from 8.89 to $4.96 \mathrm{GPa}$, by a rate of $44.21 \%$. And the secant modulus decreases from 6.17 to $3.28 \mathrm{GPa}$, by a rate of $46.84 \%$. However, the peak strain increases from $1.15 \times 10^{-2}$ to 


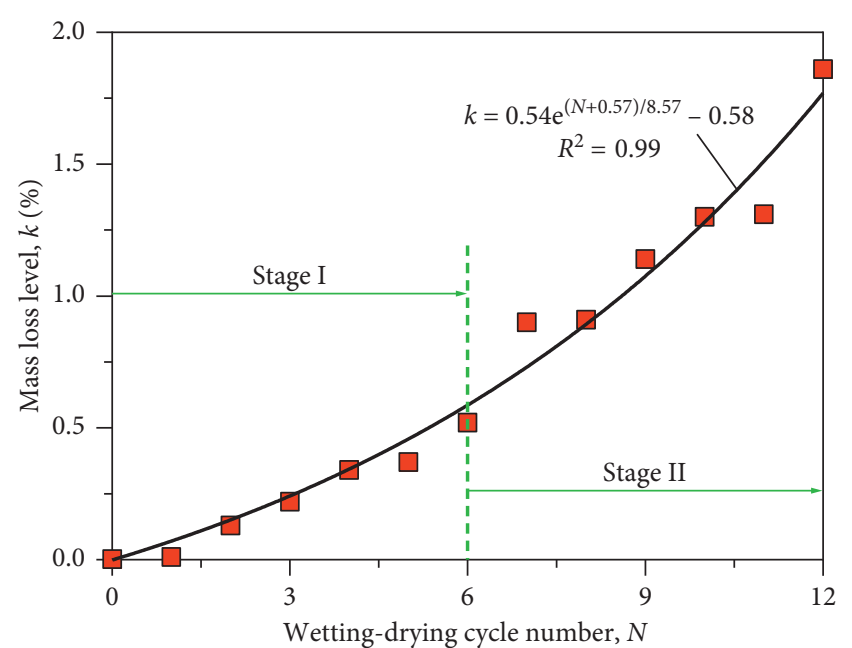

FIGURE 5: Variation in mass loss level with different wetting-drying cycle number.

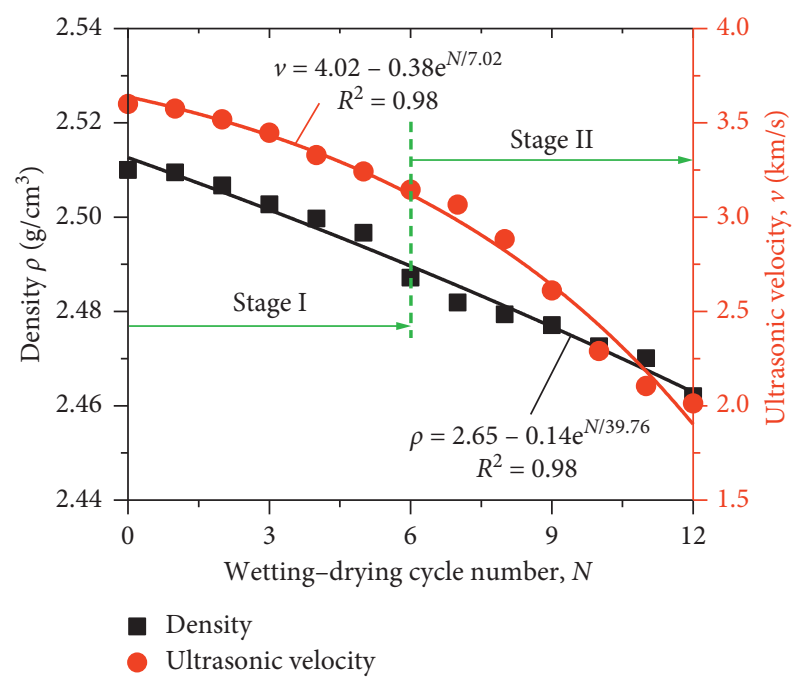

FIgURE 6: Variations in density and ultrasonic velocity with different wetting-drying cycle number.

$1.43 \times 10^{-2}$, by a rate of $24.35 \%$. In the cycle process of wetting-drying, the structural damage caused by the loss of mineral grains is one reason for the degradation of the mechanical performances of argillaceous limestones [27]. Another reason is that the wetting-drying cycle gives rise to the reduction of bonding performance among the mineral grains, leading to the decrease of bearing capacity. In general, the variations in compression strength, peak strain, elasticity modulus, and secant modulus versus $N$ can be expressed by the exponential function with the correlation coefficients of $0.90 \sim 0.98$, as follows:

$$
\begin{aligned}
\sigma_{0} & =83.40-1.24 e^{N / 3.68}, \quad R^{2}=0.98, \\
\varepsilon_{0} & =1.06+1.91 \times 10^{-3} e^{(N+28.78) / 7.76}, \quad R^{2}=0.90, \\
E_{\mathrm{a}} & =10.04-0.98 e^{N / 7.10}, \quad R^{2}=0.90, \\
E_{50} & =6.39-0.2998 e^{N / 5.09}, \quad R^{2}=0.95 .
\end{aligned}
$$

As shown in Figure 7, before and after the $6^{\text {th }}$ cycle of wetting-drying, the mechanical parameters including compression strength, peak strain, elasticity modulus, and secant modulus are presented in a staged way, which are similar to the physical parameters. In the first stage, for $N=0 \sim 6$, the compression strength, elasticity modulus, and secant modulus decrease by the rates of $3.26 \%, 4.84 \%$, and $9.08 \%$, respectively, and the peak strain increases by a rate of $5.22 \%$. In the second stage, from $6^{\text {th }}$ to $12^{\text {th }}$ wetting-drying cycle, the changing rates of compression strength, peak strain, elasticity modulus, and secant modulus are $35.26 \%$, $18.18 \%, 41.37 \%$, and $41.53 \%$, respectively, which are much larger than those in the first stage. This sectionalized feature can be explained by the SEM images, as shown in Figure 8 . With the increase in $N$, the mineral structure grew looser. Besides, the fracture phenomena among the mineral grains, caused by wetting-drying cycle, were more widespread after the $6^{\text {th }}$ cycle, which leads to the saltation in the physical and mechanical performances.

The AE count distribution of the argillaceous limestone specimens in the loading process of uniaxial compression is also dominated by the cycle effect of wetting-drying, as shown in Figure 9. When $N=0$, the AE counts are mainly concentrated near the peak stress point, but are relatively less in the early and medium periods, showing an obvious brittleness feature. When $N=6$, the obvious AE counts initiate from the time corresponding to approximately $50 \%$ of the peak stress. The larger $N$, the earlier the AE counts appear. For $N=12$, the prominent AE counts are collected in the time corresponding to approximately $20 \%$ of the peak stress. Further, the peak AE count in the loading process also appears a drastic reduction from $3714(N=0)$ to $3346(N=6)$ and then to $1484(N=12)$. This acoustic phenomenon illustrates that the wetting-drying cycle effectively reduces the brittleness of argillaceous limestones, especially after the $6^{\text {th }}$ wetting-drying cycle.

The increase in $N$ results in the variations in physical properties as well as the mechanical performances. For the rock materials, the mechanical performances are usually related to the physical properties. This correlation can contribute to the prediction of the mechanical performances based on the basic physical parameters. For instance, the experimental result from Lü et al. [28] indicated that the tensile strength of Linyi sandstone affected by high temperature displays a quadratic function with the longitudinal wave velocity in the temperature range of $25 \sim 900^{\circ} \mathrm{C}$. Kahraman [29] found an exponential relationship between the uniaxial compressive strength and sound velocity according to the summary on 48 different rocks. In this study, a linear function is applied to describe the relationships between the physical and mechanical performances, as shown in Figure 10. With the increase in mass loss level, compression strength, elasticity modulus, and secant modulus decrease gradually, while peak strain increases. However, compression strength, elasticity modulus, and secant modulus all increases in general with the increases in density and ultrasonic velocity, while peak strain decreases gradually. 


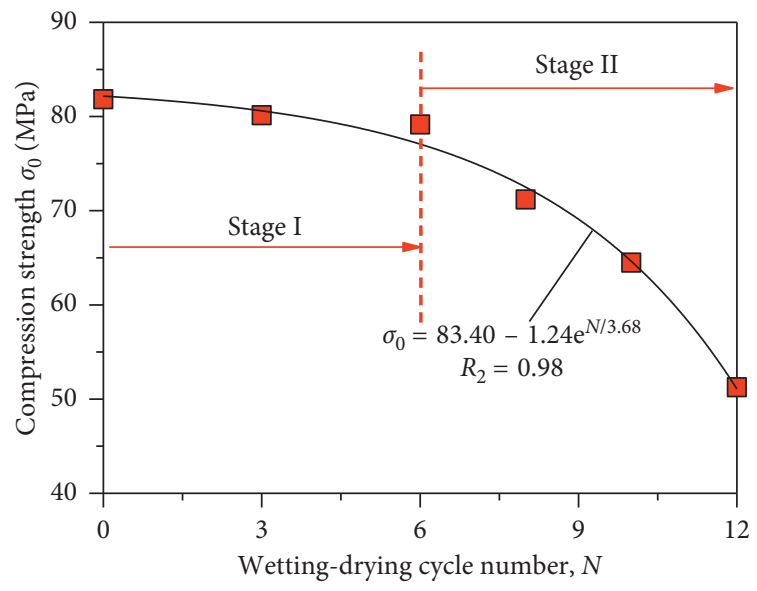

(a)

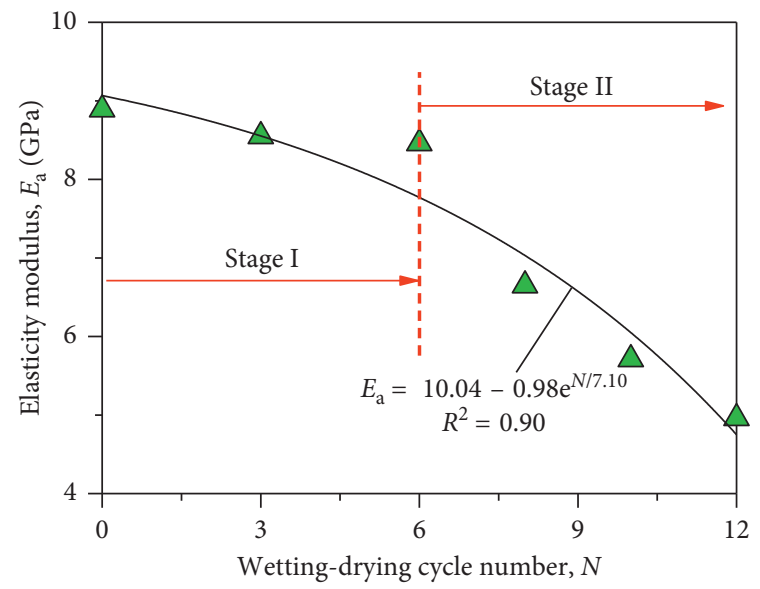

(c)

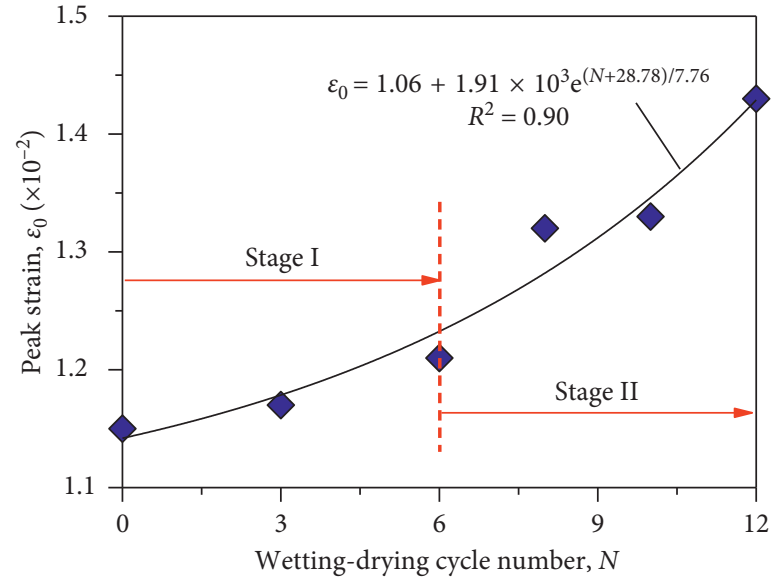

(b)

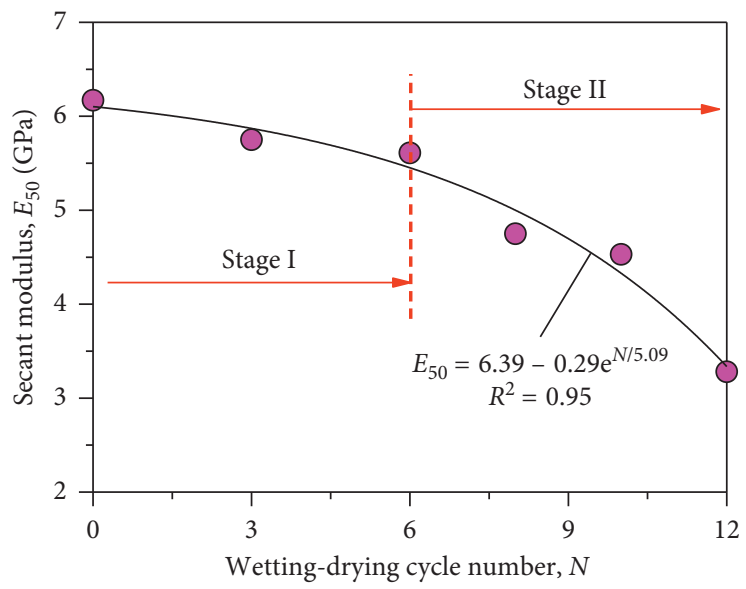

(d)

FiguRE 7: Variations in (a) compression strength, (b) peak strain, (c) elasticity modulus, and (d) secant modulus versus the wetting-drying cycle number.

TABLE 2: Mechanical and pore parameters of argillaceous limestones after the wetting-drying cycle.

\begin{tabular}{|c|c|c|c|c|c|c|c|c|c|}
\hline \multirow{2}{*}{$N$} & \multirow{2}{*}{$\sigma_{0}(\mathrm{MPa})$} & \multirow{2}{*}{$\varepsilon_{0}\left(\times 10^{-2}\right)$} & \multirow{2}{*}{$E_{0}(\mathrm{GPa})$} & \multirow{2}{*}{$E_{50}(\mathrm{GPa})$} & \multirow{2}{*}{$\phi(\%)$} & \multicolumn{4}{|c|}{ Pe (\%) } \\
\hline & & & & & & $0 \sim 0.01 \mu \mathrm{m}$ & $0.01 \sim 0.1 \mu \mathrm{m}$ & $0.1 \sim 1.0 \mu \mathrm{m}$ & $>1.0 \mu \mathrm{m}$ \\
\hline 0 & 81.83 & 1.15 & 8.89 & 6.17 & 8.73 & 0.10 & 10.18 & 87.88 & 1.84 \\
\hline 3 & 80.13 & 1.17 & 8.55 & 5.75 & 8.82 & 0.27 & 7.83 & 90.48 & 1.42 \\
\hline 6 & 79.16 & 1.21 & 8.46 & 5.61 & 8.84 & 0.23 & 6.13 & 91.32 & 2.32 \\
\hline 8 & 71.19 & 1.32 & 6.65 & 4.75 & 9.41 & 0.02 & 7.83 & 90.86 & 1.29 \\
\hline 10 & 64.49 & 1.33 & 5.71 & 4.53 & 9.52 & 0.01 & 7.06 & 91.46 & 1.47 \\
\hline 12 & 51.25 & 1.43 & 4.96 & 3.28 & 9.55 & 0.02 & 7.03 & 92.24 & 0.71 \\
\hline
\end{tabular}

4.3. Pore Structure. The porosity $\phi$ of argillaceous limestones after the wetting-drying cycle was measured by the NMR tests, as shown in Figure 11. With the increasing $N$, the porosity presents a gradually increasing trend in general, which is contrary to the compression strength, elasticity modulus, and secant modulus. As $N$ changes from 0 to 12 , the porosity increases from $8.73 \%$ to $9.55 \%$, by a rate of $9.39 \%$. The porosity also presents a sectionalized feature before and after the $6^{\text {th }}$ cycle, which is the same with other physical and mechanical parameters. For $N=6 \sim 12$, the increasing rate of porosity is $8.03 \%$, which is much larger than that $(1.26 \%)$ for $N=0 \sim 6$.

The $T_{2}$ curves of the argillaceous limestone specimens after the wetting-drying cycle from the NMR tests are shown in Figure 12. The $T_{2}$ curves all present a single-peak feature in general, reaching the peaks in $T_{2}=2.967 \sim 3.181 \mathrm{~ms}$. With the increase in $N$ from 0 to 12 , the peak signal value gradually increases, from 3188.49 to 3758.72 , by a rate of $17.88 \%$. Due to the small scale, the rock pore can be simplified as the ball. The pore distributions of the argillaceous limestone 


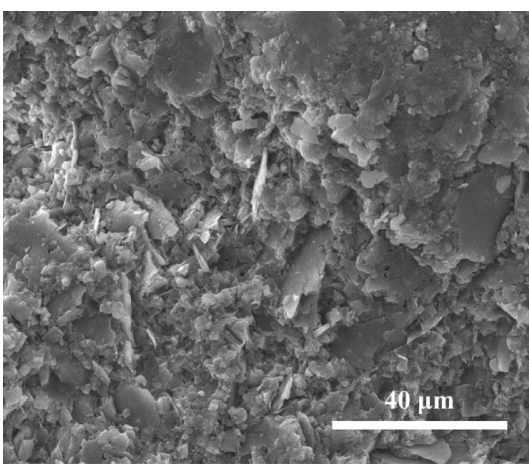

(a)

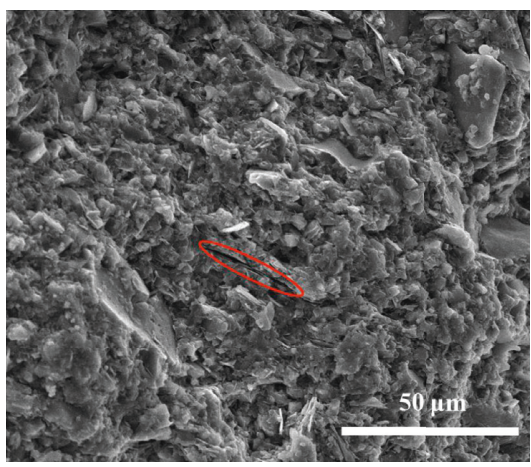

(c)

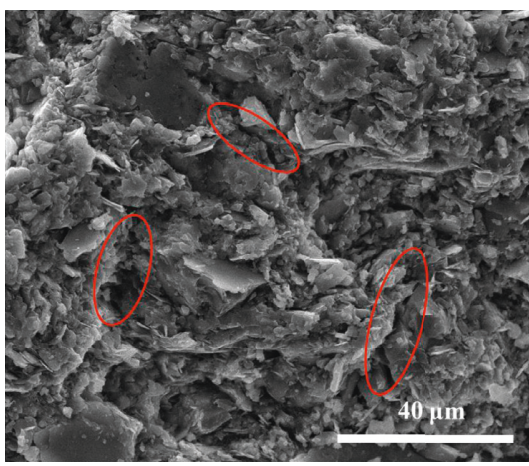

(e)

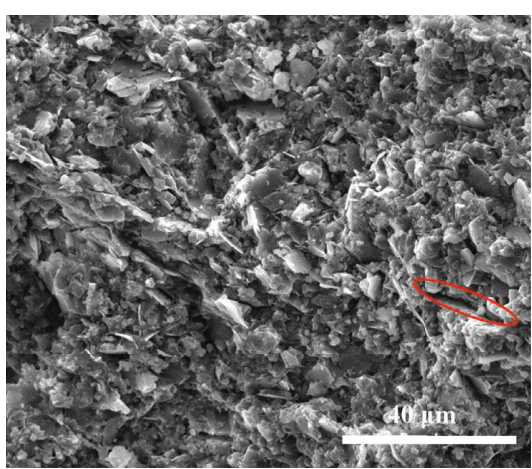

(b)

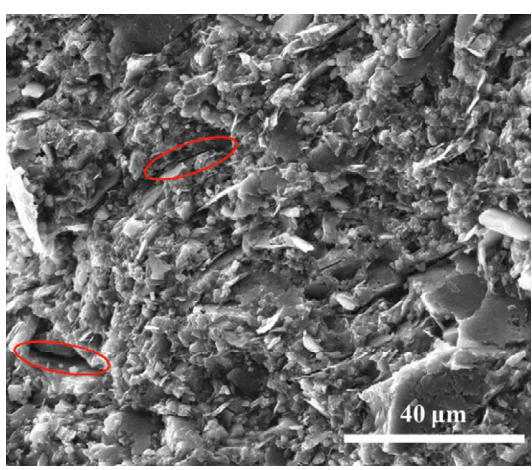

(d)

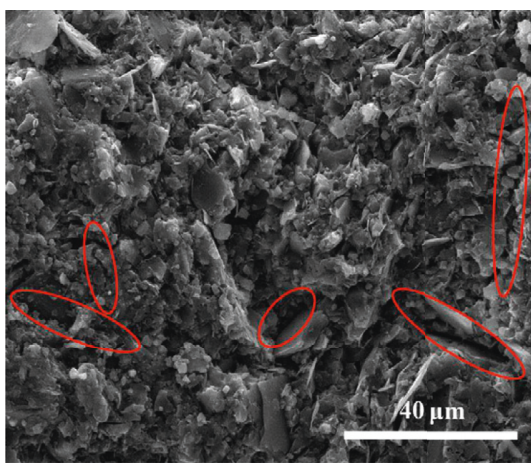

(f)

Figure 8: SEM images of argillaceous limestones after the cycle effect of wetting-drying: (a) $N=0$, (b) $N=3$, (c) $N=6$, (d) $N=8$, (e) $N=10$, and (f) $N=12$.

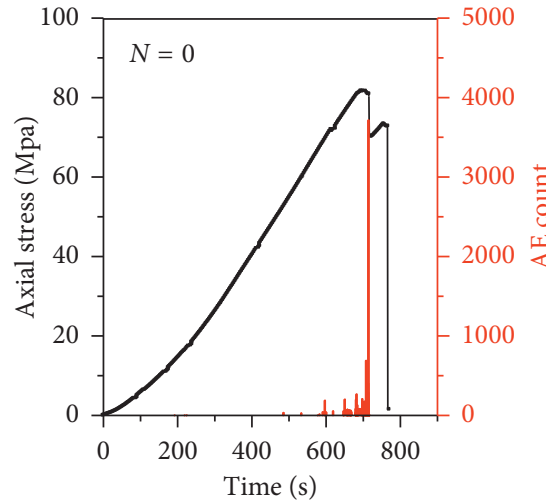

(a)

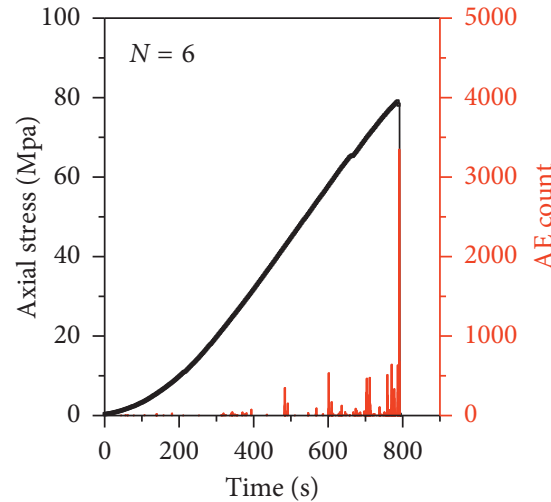

(b)

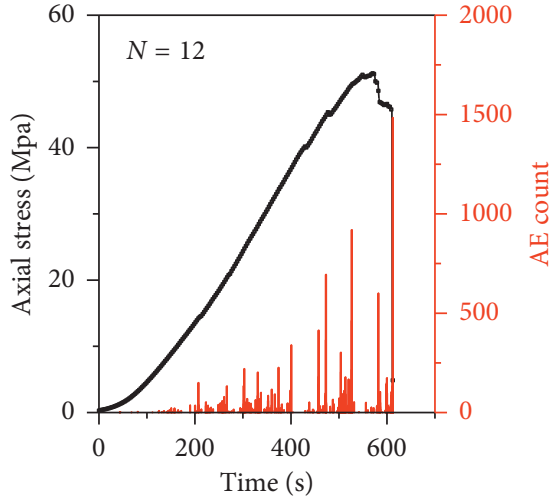

(c)

FIGURE 9: AE count distributions of the argillaceous limestone specimens in the loading process of uniaxial compression. 


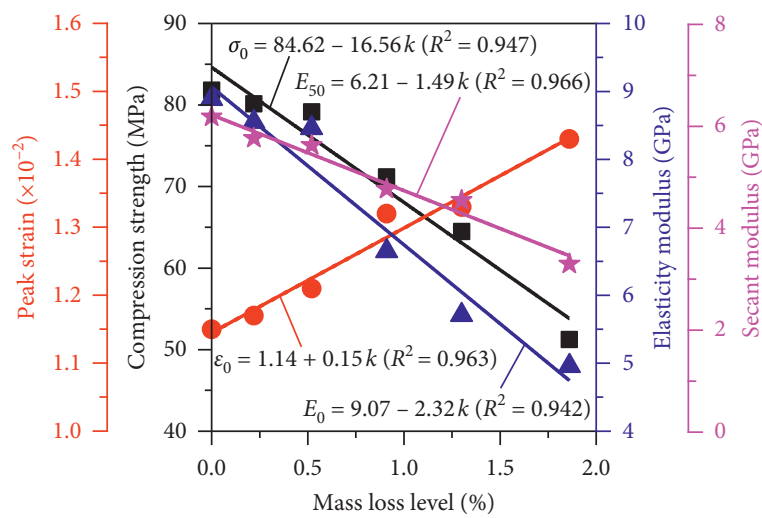

(a)

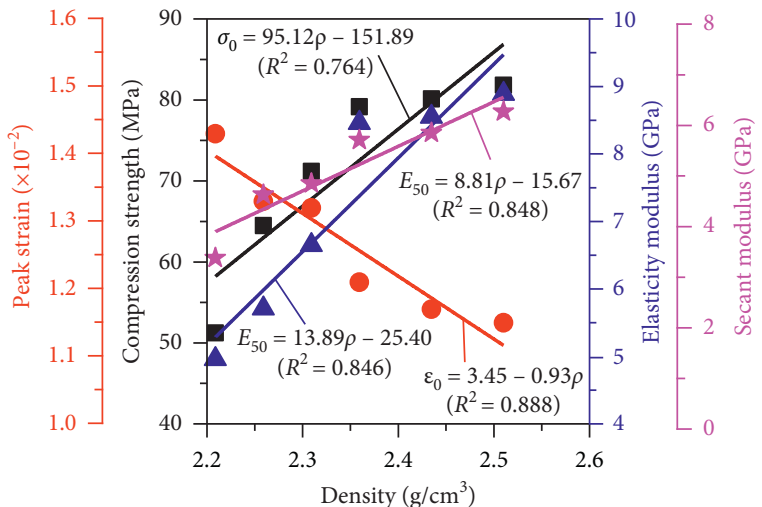

(b)

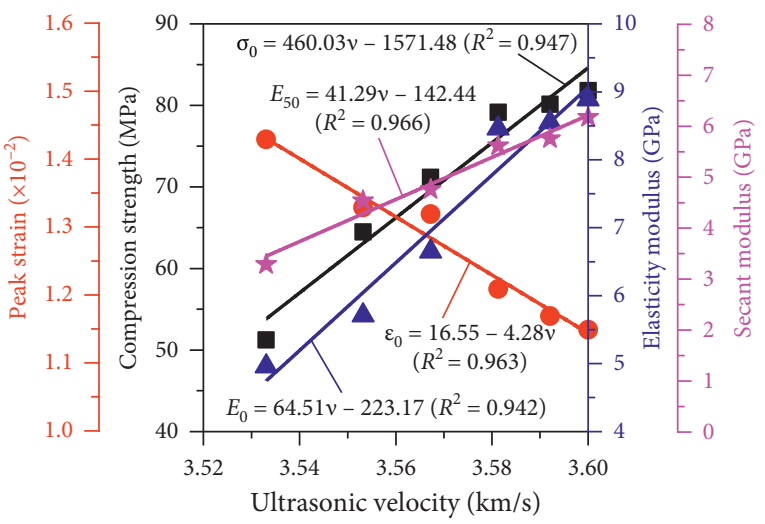

(c)

FiguRE 10: Relationships between physical and mechanical parameters. (a) $\sigma_{0}, \varepsilon_{0}, E_{\mathrm{a}}, E_{50}$ vs. $k$, (b) $\sigma_{0}, \varepsilon 0, E_{\mathrm{a}}, E_{50}$ vs. $\rho$, and (c) $\sigma_{0}, \varepsilon_{0}, E_{\mathrm{a}}, E_{50}$ vs. $v$.

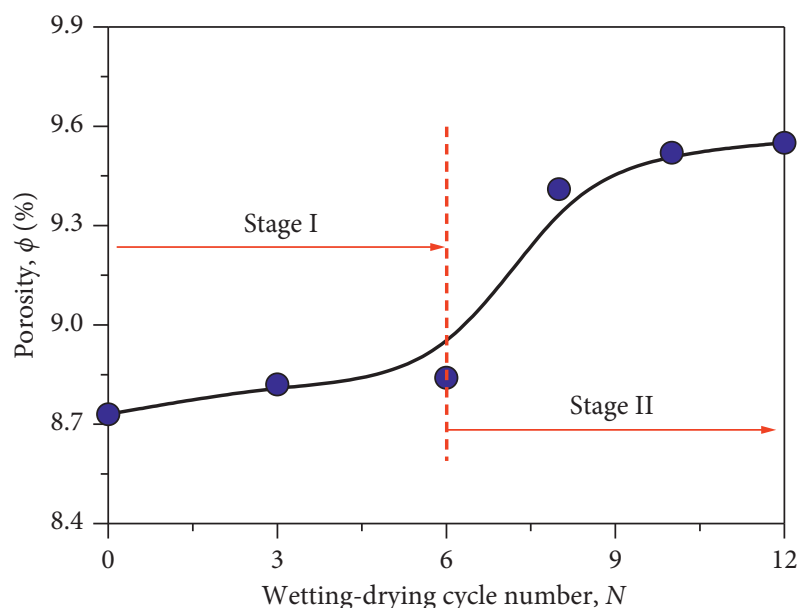

FIGURE 11: Variation in porosity versus the wetting-drying cycle number.

specimens after the wetting-drying cycle are calculated from the $T_{2}$ curves. According to the ball radius $r$, the pores can be divided into four groups by $r=0 \sim 0.01 \mu \mathrm{m}, 0.01 \sim 0.1 \mu \mathrm{m}$, $0.1 \sim 1.0 \mu \mathrm{m}$ and $>1.0 \mu \mathrm{m}$, respectively, and the volume ratio Pe of each group is listed in Table 2 , in which the volume ratio Pe is the ratio of pore volume in each group to the total pore volume.

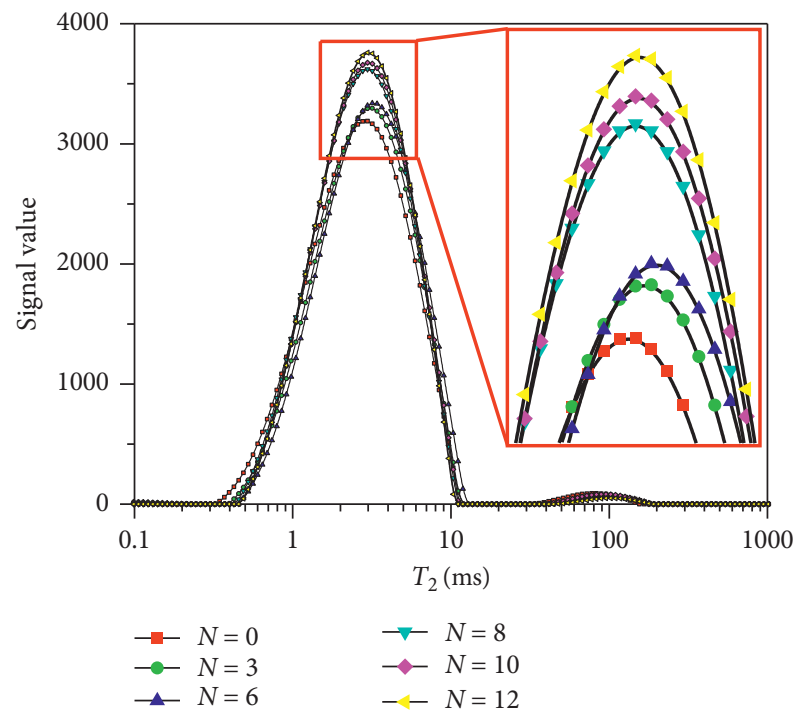

FIGURE 12: T2 curves of argillaceous limestones after the cycle effect of wetting-drying.

As tabulated in Table 2, the maximal volume ratio is focused on the pore radius between 0.1 and $1.0 \mu \mathrm{m}$, which occupies $90.71 \%$ of the total pore volume. The second large volume ratio is obtained in the radius range of $0.01 \sim 0.1 \mu \mathrm{m}$, which occupies $7.68 \%$ of the total pore volume. The 


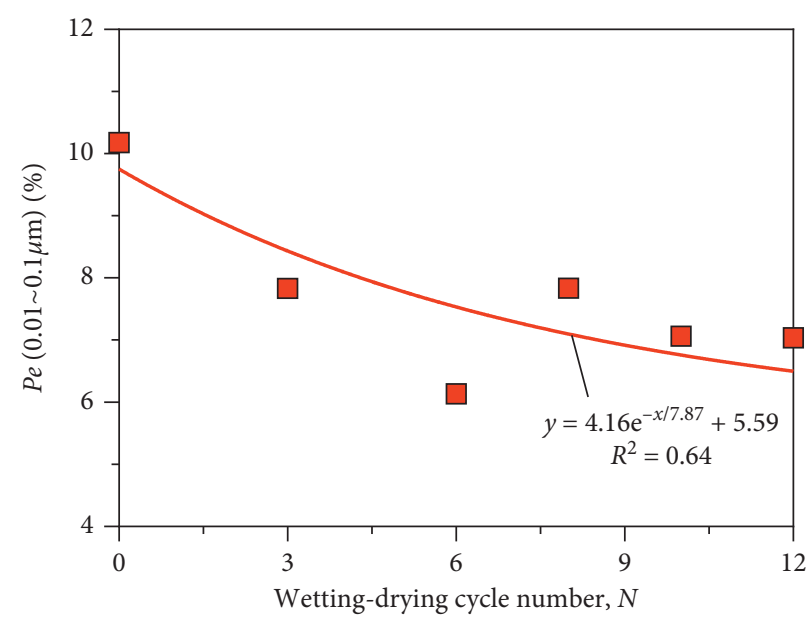

(a)

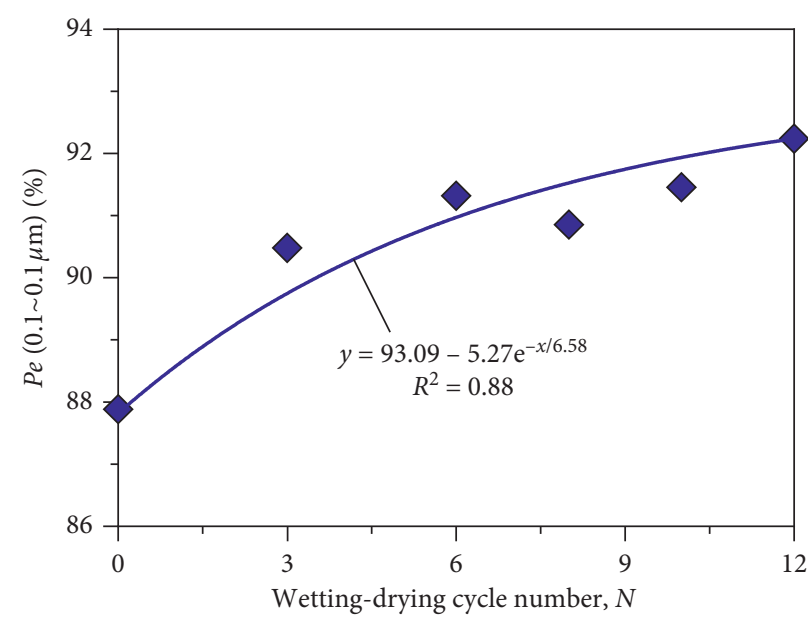

(b)

Figure 13: Variations in Pe $(0.01 \sim 0.1 \mu \mathrm{m})$ and $\mathrm{Pe}(0.1 \sim 1.0 \mu \mathrm{m})$ versus the wetting-drying cycle number.

minimum volume ratio is located in $\operatorname{Pe}(0 \sim 0.01 \mu \mathrm{m})$, with the mean value of $0.11 \%$. This illustrates that $\mathrm{Pe}(0.1 \sim 1.0 \mu \mathrm{m})$ and $\mathrm{Pe}(0.01 \sim 0.1 \mu \mathrm{m})$ dominate the pore structure of argillaceous limestones, having a total volume ratio of $97.45 \%$ $99.27 \%$. The variations in $\mathrm{Pe}(0.1 \sim 1.0 \mu \mathrm{m})$ and $\mathrm{Pe}$ $(0.01 \sim 0.1 \mu \mathrm{m})$ versus $N$ are shown in Figure 13. With the increase in $N, \operatorname{Pe}(0.01 \sim 0.1 \mu \mathrm{m})$ gradually decreases in general, while $\mathrm{Pe}(0.1 \sim 1.0 \mu \mathrm{m})$ presents an approximately increasing trend. Under the wetting-drying cycle effect, clay minerals run away from the argillaceous limestone, resulting in the initiation of new pores and the development of original pores. Meanwhile, the loss of clay minerals also brings rise to the connections among pores [30]. Generally, the wetting-drying cycle leads to the change in argillaceous limestone from small pore to relatively large pore, which is highly consistent with the SEM results. These results commendably interpret the changes in the physical and mechanical performances.

\section{Conclusions}

In this study, argillaceous limestones from the Liupanshan tunnel (China) were saturated and treated by the wettingdrying cycle to investigate the variations in the physical and mechanical performances. The SEM and NMR tests were also conducted on the specimens to reveal the microscopic feature and structure. Some conclusions can be obtained as follows:

(1) The saturation effect promotes the dissolution of clay minerals in argillaceous limestone and reduces the friction among the mineral grains, which leads to attenuations in the strength and deformation performances of the specimens. The cohesion and friction in the saturated state decrease by $25.90 \%$ and $6.59 \%$, respectively, compared with those in the natural state.

(2) With an increase in the wetting-drying cycle number, density, ultrasonic velocity, compression strength, elasticity modulus, and secant modulus decrease gradually, while mass loss level increases. The variation process of these physical and mechanical parameters follows the exponential function with the increase in the wetting-drying cycle number in general.

(3) Wetting-drying cycle effect gives rise to the development of microscopic fractures, as well as the increase in porosity, especially after the $6^{\text {th }}$ cycle. The pore structure of argillaceous limestone under the wetting-drying cycle effect also redistributes. The percentage of the small pore $(0.01 \sim 0.1 \mu \mathrm{m})$ decreases gradually, while that of the relatively large pore $(0.1 \sim 1.0 \mu \mathrm{m})$ increases in general.

\section{Data Availability}

The data used to support the findings of this study are available from the corresponding author upon request.

\section{Conflicts of Interest}

The authors declare that they have no conflicts of interest.

\section{Acknowledgments}

This paper was financially supported by the National Natural Science Foundation of China (nos. 51704279, 51504247, and 51734009) and the Natural Science Foundation of Jiangsu Province of China (no. BK20170270).

\section{References}

[1] Y. Nara, H. Yamanaka, Y. Oe, and K. Kaneko, "Influence of temperature and water on subcritical crack growth parameters and long-term strength for igneous rocks," Geophysical Journal International, vol. 193, no. 1, pp. 47-60, 2013.

[2] D. Ma, X. Cai, Q. Li, and H. Duan, "In-situ and numerical investigation of groundwater inrush hazard from grouted 
karst collapse pillar in longwall mining," Water, vol. 10, no. 9, p. 1187, 2018.

[3] E. Kim and H. Changani, "Effect of water saturation and loading rate on the mechanical properties of red and buff sandstones," International Journal of Rock Mechanics and Mining Sciences, vol. 88, pp. 23-28, 2016.

[4] E. Rossi, M. A. Kant, C. Madonna, M. O. Saar, and P. Rudolf von Rohr, "The effects of high heating rate and high temperature on the rock strength: feasibility study of a thermally assisted drilling method," Rock Mechanics and Rock Engineering, vol. 51, no. 9, pp. 2957-2964, 2018.

[5] C. K. Ballantyne, P. Wilson, C. Schnabel, and S. Xu, "Lateglacial rock slope failures in north-west Ireland: age, causes and implications," Journal of Quaternary Science, vol. 28, no. 8, pp. 789-802, 2013.

[6] J. Yu, T.-B. Li, J.-Z. Zhang, and Y.-Y. Cai, "Stress characteristics of surrounding rocks for inner water exosmosis in high-pressure hydraulic tunnels," Journal of Central South University, vol. 21, no. 7, pp. 2970-2976, 2014.

[7] Q. Yin, G. Ma, H. Jing et al., "Hydraulic properties of 3D rough-walled fractures during shearing: an experimental study," Journal of Hydrology, vol. 555, pp. 169-184, 2017.

[8] D. Ma, H. Duan, J. Liu, X. Li, and Z. Zhou, "The role of gangue on the mitigation of mining-induced hazards and environmental pollution: an experimental investigation," Science of the Total Environment, vol. 664, pp. 436-448, 2019.

[9] D. Ma, H. Duan, X. Li, Z. Li, Z. Zhou, and T. Li, "Effects of seepage-induced erosion on nonlinear hydraulic properties of broken red sandstones," Tunnelling and Underground Space Technology, vol. 91, article 102993, 2019.

[10] D. Li, L. N. Y. Wong, G. Liu, and X. Zhang, "Influence of water content and anisotropy on the strength and deformability of low porosity meta-sedimentary rocks under triaxial compression," Engineering Geology, vol. 126, pp. 46-66, 2012.

[11] Z. Zhou, X. Cai, D. Ma, W. Cao, L. Chen, and J. Zhou, "Effects of water content on fracture and mechanical behavior of sandstone with a low clay mineral content," Engineering Fracture Mechanics, vol. 193, pp. 47-65, 2018.

[12] N. Li, Y. M. Zhu, B. Su, and S. Gunter, "A chemical damage model of sandstone in acid solution," International Journal of Rock Mechanics and Mining Sciences, vol. 40, no. 2, pp. 243-249, 2003.

[13] T. Han, J. Shi, and X. Cao, "Fracturing and damage to sandstone under coupling effects of chemical corrosion and freeze-thaw cycles," Rock Mechanics and Rock Engineering, vol. 49, no. 11, pp. 4245-4255, 2016.

[14] Y.-Y. Cai, J. Yu, G.-F. Fu, and H. Li, "Experimental investigation on the relevance of mechanical properties and porosity of sandstone after hydrochemical erosion," Journal of Mountain Science, vol. 13, no. 11, pp. 2053-2068, 2016.

[15] H. P. Lisabeth and W. Zhu, "Effect of temperature and pore fluid on the strength of porous limestone," Journal of Geophysical Research: Solid Earth, vol. 120, no. 9, pp. 6191-6208, 2015.

[16] W. J. Luo and X. L. Yang, "3D stability of shallow cavity roof with arbitrary profile under influence of pore water pressure," Geomechanics and Engineering, vol. 16, no. 6, pp. 569-575, 2018.

[17] M. N. Bidgoli and L. R. Jing, "Water pressure effects on strength and deformability of fractured rocks under low confining pressures," Rock Mechanics and Rock Engineering, vol. 48, no. 3, pp. 971-985, 2015.

[18] C. Cheng, X. Li, S. Li, and B. Zheng, "Failure behavior of granite affected by confinement and water pressure and its influence on the seepage behavior by laboratory experiments," Materials, vol. 10, no. 7, p. 798, 2017.

[19] T. Inoue, S. Yamaguchi, and J. M. Nelson, "The effect of wetdry weathering on the rate of bedrock river channel erosion by saltating gravel," Geomorphology, vol. 285, pp. 152-161, 2017.

[20] Z. Qin, X. Chen, and H. Fu, "Damage features of altered rock subjected to drying-wetting cycles," Advances in Civil Engineering, vol. 2018, Article ID 5170832, 10 pages, 2018.

[21] Z. Zhou, X. Cai, D. Ma, L. Chen, S. Wang, and L. Tan, "Dynamic tensile properties of sandstone subjected to wetting and drying cycles," Construction and Building Materials, vol. 182, pp. 215-232, 2018.

[22] Z. Zhao, J. Yang, D. Zhang, and H. Peng, "Effects of wetting and cyclic wetting-drying on tensile strength of sandstone with a low clay mineral content," Rock Mechanics and Rock Engineering, vol. 50, no. 2, pp. 485-491, 2017.

[23] Z. Zhou, X. Cai, D. Ma et al., "Water saturation effects on dynamic fracture behavior of sandstone," International Journal of Rock Mechanics and Mining Sciences, vol. 114, pp. 46-61, 2019.

[24] S. Huang, J. Wang, Z. Qiu, and K. Kang, "Effects of cyclic wetting-drying conditions on elastic modulus and compressive strength of sandstone and mudstone," Processes, vol. 6, no. 12, p. 234, 2018.

[25] A. Özbek, "Investigation of the effects of wetting-drying and freezing-thawing cycles on some physical and mechanical properties of selected ignimbrites," Bulletin of Engineering Geology and the Environment, vol. 73, no. 2, pp. 595-609, 2014.

[26] Q. Sun and Y. Zhang, "Combined effects of salt, cyclic wetting and drying cycles on the physical and mechanical properties of sandstone," Engineering Geology, vol. 248, pp. 70-79, 2019.

[27] B. Du, H. Bai, and G. Wu, "Dynamic compression properties and deterioration of red-sandstone subject to cyclic wet-dry treatment," Advances in Civil Engineering, vol. 2019, Article ID 1487156, 10 pages, 2019.

[28] C. Lü, Q. Sun, W. Zhang, J. Geng, Y. Qi, and L. Lu, “The effect of high temperature on tensile strength of sandstone," Applied Thermal Engineering, vol. 111, pp. 573-579, 2017.

[29] S. Kahraman, "Evaluation of simple methods for assessing the uniaxial compressive strength of rock," International Journal of Rock Mechanics and Mining Sciences, vol. 38, no. 7, pp. 981-994, 2001.

[30] Y. Zhao, S. Ren, D. Jiang, R. Liu, J. Wu, and X. Jiang, "Influence of wetting-drying cycles on the pore structure and mechanical properties of mudstone from Simian Mountain," Construction and Building Materials, vol. 191, pp. 923-931, 2018. 


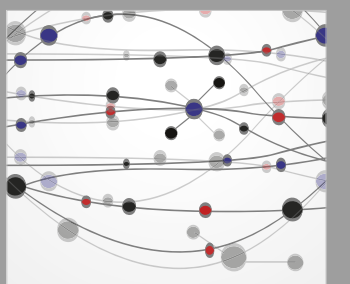

The Scientific World Journal
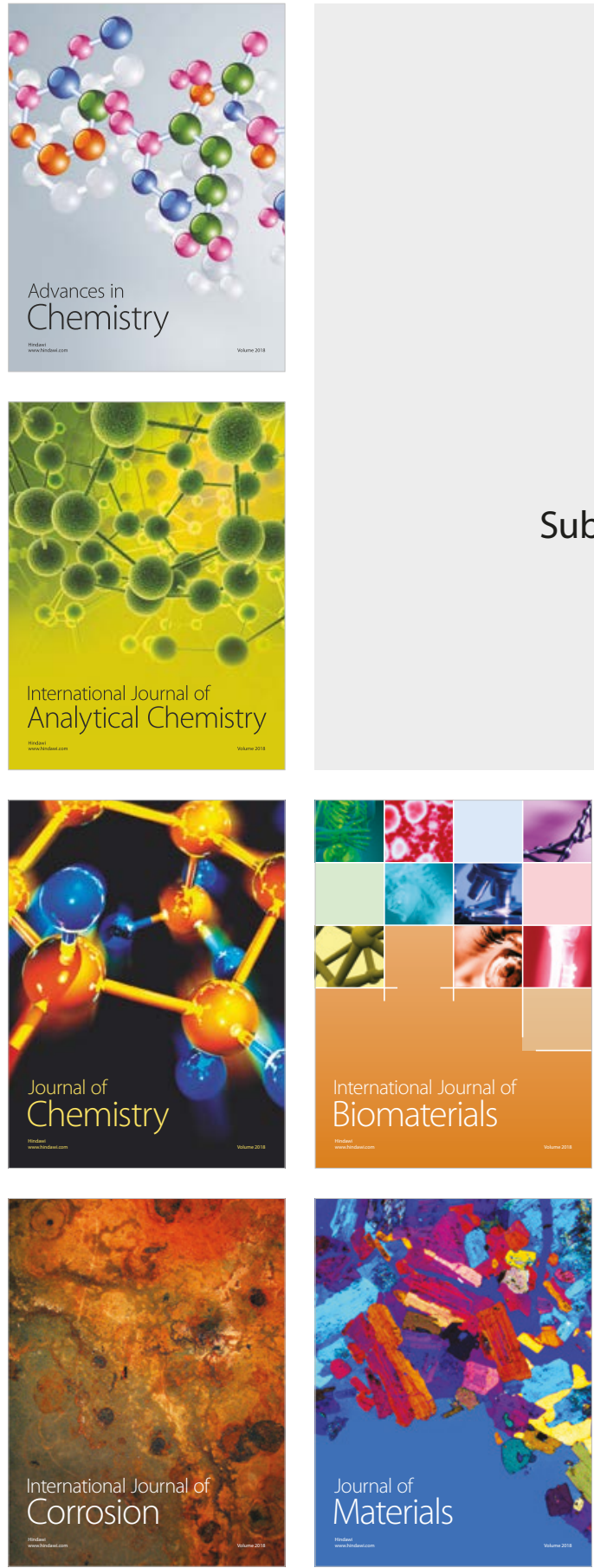

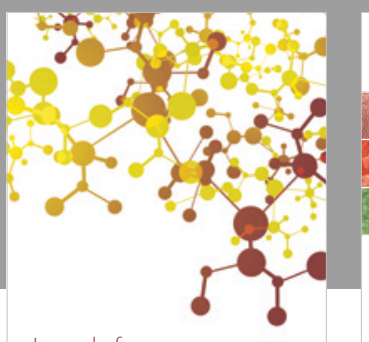

Journal of

Applied Chemistry
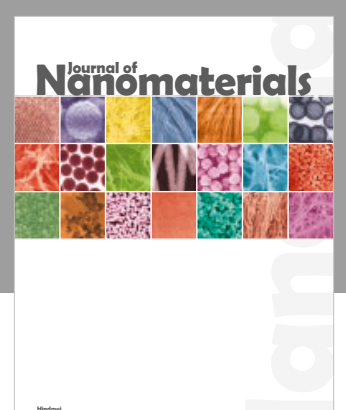

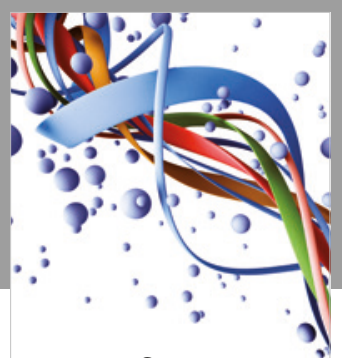

Scientifica

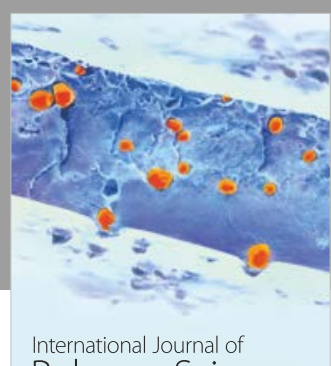

Polymer Science

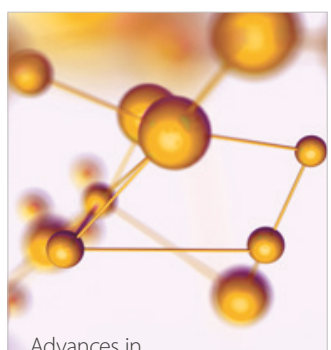

Physical Chemistry
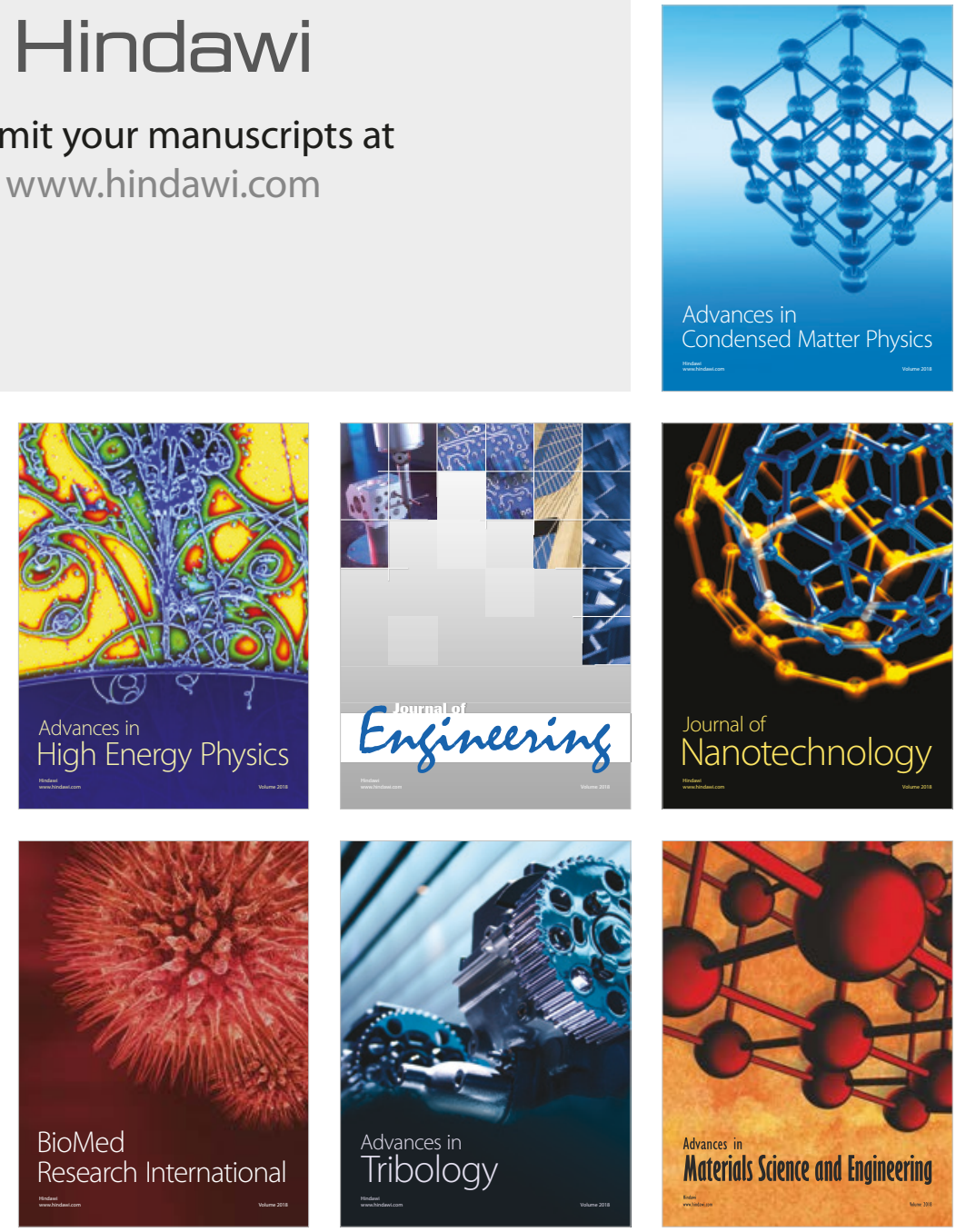